\title{
Consecutive cold/hot underwater snaring with a single hybrid snare for resection of large sessile serrated lesions when cold snaring fails
}

We present two endoscopic resections using consecutive cold and hot snaring (Olympus SnareMaster, Tokyo, Japan) with a single hybrid snare for two sessile serrated lesions (SSLs). The lesions were classified as Paris Ila, NICE I, Kudo IIO,
CONECCT Is [1], were $>10 \mathrm{~mm}$ in diameter, and were located in the right colon. The underwater technique was initially used because of the higher reported en bloc resection rate with lower risk of perforation [2,3]. For the first lesion, con-

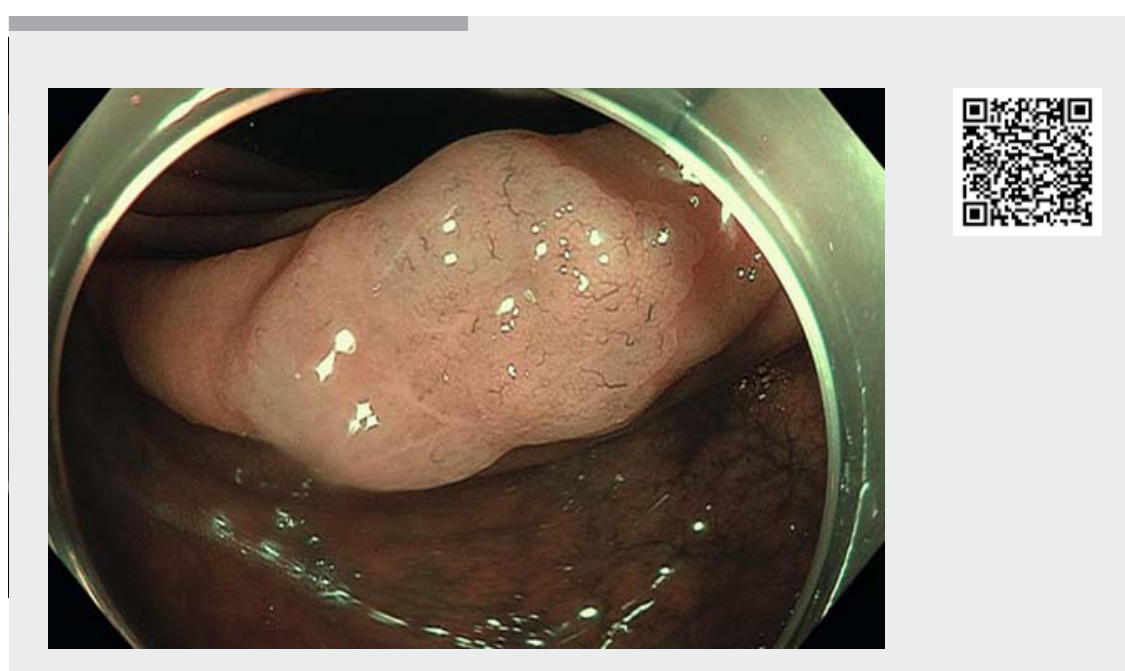

Video 1 Consecutive cold/hot underwater snaring.

(n)

ventional cold snare resection was attempted but was not possible because of the quantity of tissue trapped within the snare, preventing complete section ( $\triangleright$ Fig. 1 a, b, $\triangleright$ Video 1). As en bloc cold resection was not feasible, the hybrid snare was connected to the monopolar electrosurgical unit (ERBE VIO 300, polypectomy, ENDO Q 2, Forced Coag 35 W; Erbe Elektromedizin $\mathrm{GmbH}$, Tübingen, Germany), and current was used to achieve cutting of the tissue caught within the snare, leading to successful resection of the snared lesion ( $\mathbf{F i g . 1} \mathbf{c}$ ). In the second case of a $25-\mathrm{mm}$ SSL ( $\vee$ Fig.2), piecemeal resection was successful using this consecutive cold and hot underwater snaring (CHUS) technique ( $\triangleright$ Video 1 )

To the best of our knowledge, this is one of the first video cases reporting the CHUS technique either for en bloc or piecemeal resection of SSLs. Our cases are particularly interesting because the underwater technique allowed en bloc resection of polyps $>10 \mathrm{~mm}$ (shrinking
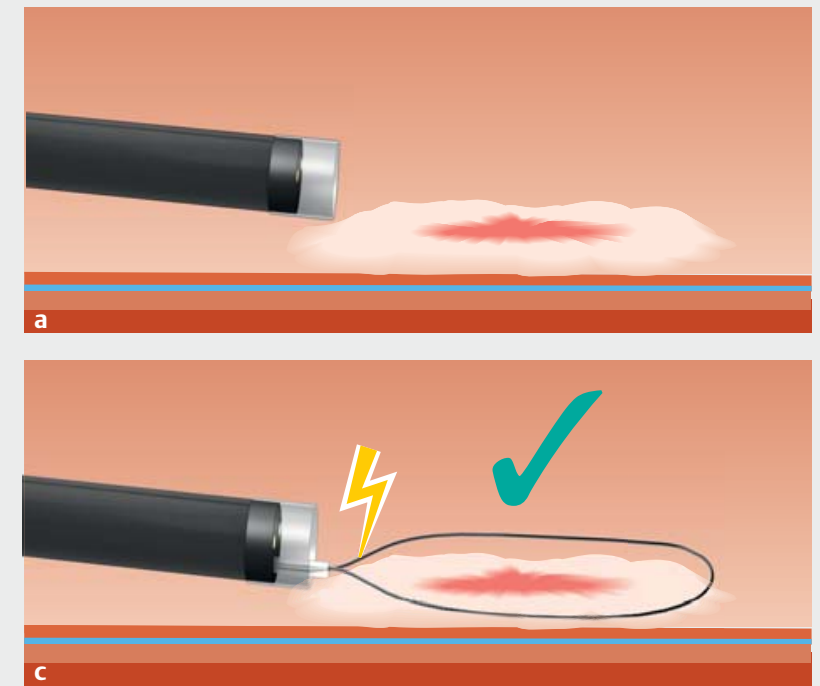
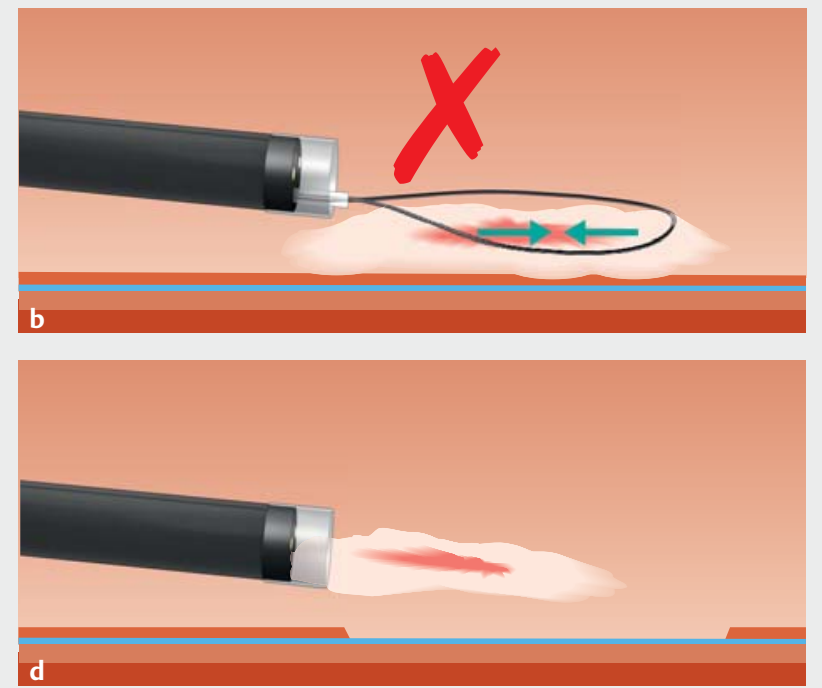

- Fig. 1 Consecutive cold/hot underwater snaring. a Sessile serrated lesion. b Failure of cold underwater en bloc resection. $\mathbf{c}$ Hot underwater resection. $\mathbf{d}$ Retrieval of the polypectomy specimen for hystologic examination. 

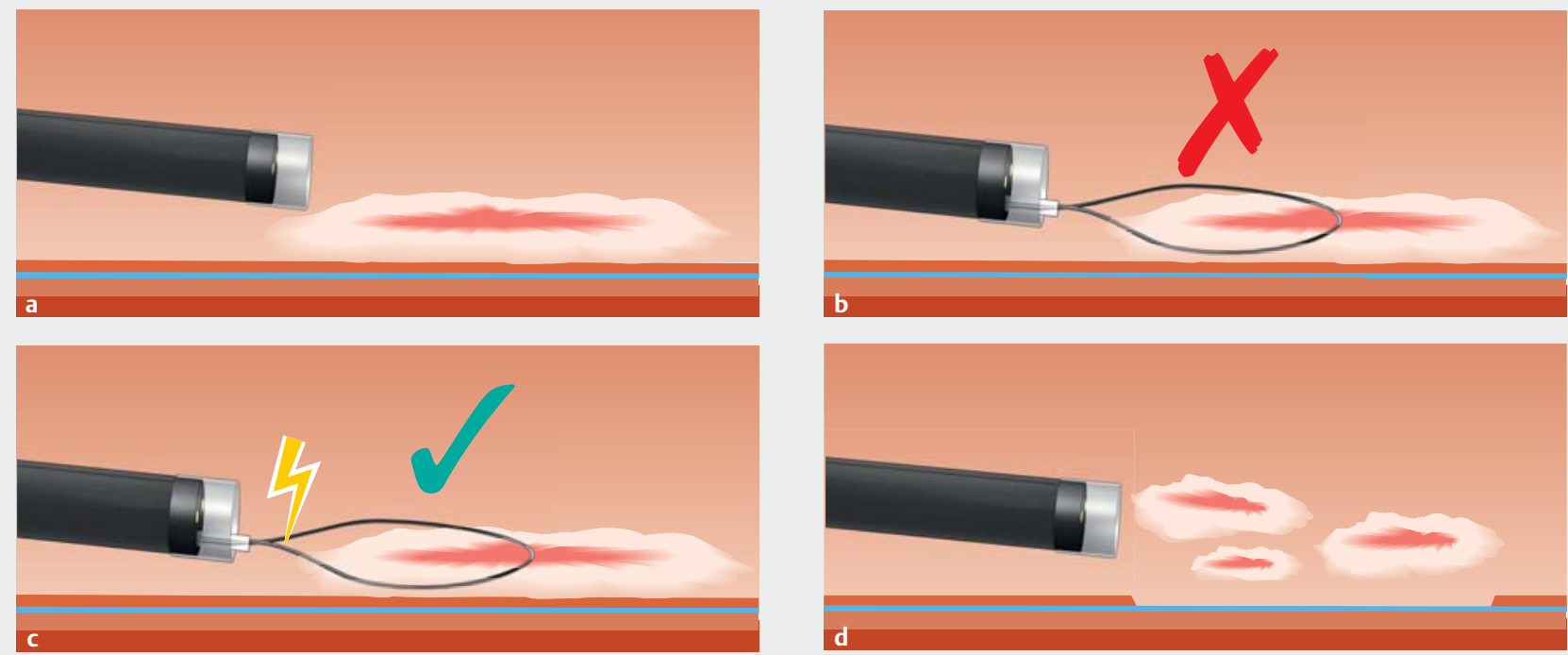

Fig. 2 Consecutive cold/hot underwater snaring. a Large sessile serrated lesion in the right colon. b Failure of piecemeal underwater cold resection. $\mathbf{c}$ Effective hot piecemeal underwater resection. $\mathbf{d}$ Retrieval of the polypectomy specimens.

effect), and the consecutive hybrid cold/ hot snare seems to have a lower risk of complications (delayed bleeding, perforation) compared with the standard polypectomy technique after submucosal injection.

Our data need validation in a prospective multicenter study comparing this technique with conventional endoscopic mucosal resection.

Endoscopy_UCTN_Code_TTT_1AQ_2AD

\section{Competing interests}

Drs. Rivory, Ponchon, and Pioche are consultants for Olympus, Japan. All other authors declare that they have no conflict of interest.

The authors

\section{Alexandru Lupu ${ }^{1,2}$, Jérôme Rivory ${ }^{1}$, Martin}

Fabritius ${ }^{1}$, Florian Rostain ${ }^{1}$, Thierry Ponchon ${ }^{1}$, Mathieu Pioche ${ }^{1}$

1 Gastroenterology and Endoscopy Department, Edouard Herriot Hospital, Lyon, France

2 Gastroenterology and Endoscopy Department, Fundeni Hospital, Bucharest, Romania
Corresponding author

\section{Alexandru Lupu, MD}

Gastroenterology and Endoscopy

Department, Edouard Herriot Hospital, $5 \mathrm{Pl}$ Arsonval, Lyon 69003, France

Fax: +33-4-72110147

alexandru.c.lupu@gmail.com

\section{References}

[1] Fabritius M, Gonzalez JM, Becq A et al. A simplified table using validated diagnostic criteria is effective to improve characterization of colorectal polyps: the CONECCT teaching program. Endosc Int Open 2019; 7: E1197-E1206

[2] Yamashina T, Uedo N, Akasaka T et al. Comparison of underwater vs conventional endoscopic mucosal resection of intermediate-size colorectal polyps. Gastroenterology 2019; 157: 451-461

[3] Spadaccini M, Fuccio L, Lamonaca L et al. Underwater EMR for colorectal lesions: a systematic review with meta-analysis. Gastrointest Endosc 2019; 89: 1109-1116

\section{Bibliography}

DOI https://doi.org/10.1055/a-1085-9447

Published online: 22.1.2020

Endoscopy 2020; 52: E241-E242

(c) Georg Thieme Verlag KG

Stuttgart · New York

ISSN 0013-726X

\section{ENDOSCOPY E-VIDEOS \\ https://eref.thieme.de/e-videos}

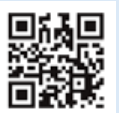

Endoscopy E-Videos is a free access online section, reporting on interesting cases and new techniques in gastroenterological endoscopy. All papers include a high quality video and all contributions are freely accessible online.

This section has its own submission website at

https://mc.manuscriptcentral.com/e-videos 